\title{
NUMERIČKA SIMULACIJA DVOFAZNOG STRUJANJA I RAZMENE TOPLOTE U VERTIKALNOM GENERATORU PARE
}

\section{NUMERICAL SIMULATION OF TWO-PHASE FLOW AND HEAT TRANSFER IN THE VERTICAL STEAM GENERATOR}

\author{
Ivan JOKSIMOVIĆ, Milan M. PETROVIĆ, Vladimir STEVANOVIĆ
}

Mašinski fakultet Univerziteta u Beogradu, Beograd

ivan.joksimovic93@gmail.com,mlpetrovic@mas.bg.ac.rs, vstevanovic@mas.bg.ac.rs

\begin{abstract}
U radu je predstavljen dvodimenzijski termohidraulički model strujanja dvofazne mešavine oko snopa cevi vertikalnog generatora pare, kao i model za proračun toplotnog fluksa između predajnika $i$ prijemnika toplote. Model dva fluida je primenjen za simulaciju strujanja dvofazne mešavine na strani prijemnika toplote i zasnovan je na jednačinama bilansa mase, količine kretanja i energije za svaku fazu pojedinačno. Procesi na međufaznim razdelnim površinama su modelirani na osnovu odgovarajućih konstitutivnih korelacija. Takođe, u radu su predstavljeni različiti načini modeliranja sile međufaznog trenja, koji se koriste u komercijalnim softverskim paketima za CFD simulacije i programima za analize sigurnosti nuklearnih reaktora. Predviđanje toplotnog fluksa izvršeno je modelom razmene toplote, koji obuhvata mehanizme jednofazne konvekcije, pothlađenog ključanja i razvijenog mehurastog ključanja. Rezultati dobijeni numeričkom simulacijom su upoređeni sa izmerenim vrednostima dostupnim u literaturi. Razvijeni model predstavlja podršku pri projektovanju generatora pare, a rezultati pružaju detaljan uvid u termohidrauličke parametre procesa.
\end{abstract}

Ključne reči: Vertikalni generator pare, dvofazno strujanje, numerička simulacija,

In this paper is presented a two-dimensional, thermal-hydraulic, two-fluid model of two-phase flow around tubes in a bundle at the secondary shell side of the vertical steam generator. A model for the prediction of heat transfer from the primary to the secondary side is also included. The two-fluid model is applied for the two-phase flow simulation at the shell side of the steam generator and it is based on mass, momentum and energy balance equations for each phase. Interface processes are determined by closure laws. Furthermore, different ways of modelling interfacial friction force are presented as used in commercial CFD software and nuclear reactor safety codes. Prediction of heat flux is performed by using a heat transfer model that includes mechanisms of single-phase convection and subcooled and saturated flow boiling. The obtained results are compared with measured data available in the literature. The developed model is a support for the design of steam generators. The obtained results represent a detailed insight into thermal-hydraulic process of the vertical steam generator.

Key words: Vertical steam generator, Two-phase flow, Numerical simulation

\section{Uvod}

Vertikalni generator pare je razmenjivač toplote u kome predajnik toplote (primarni fluid) struji unutar cevi u vertikalnom snopu, a prijemnik toplote (sekundarni fluid ) se zagreva i nakon dostizanja uslova saturacije ključa u prostoru oko cevi. Generatori pare nalaze primenu u termoenergetskim i procesnim postrojenjima.

Efikasan i bezbedan rad generatora pare zavisi od termohidrauličkih parametara na njegovoj sekundarnoj strani. Visoke vrednosti masenog fluksa dvofazne mešavine dovode do vibracija i zamora materijala cevi, nagle promene temperaturskog polja mogu dovesti do termičkih naprezanja, dok visoke vrednosti zapreminskog udela pare mogu dovesti do zasušenja, krize razmene toplote i termičkog oštećenja cevi. Pojava vrtloga u strujnom prostoru može prouzrokovati taloženje soli na cevima. Za pouzdan rad generatora pare neophodno je sagledavanje strujnih i termičkih procesa pri projektovanju i analizama radnih uslova. Ispitivanje radnih uslova najčešće nije moguće zbog konstrukcijskih ograničenja, pa se ova ispitivanja vrše eksperimentalno na skaliranim modelima i numeričkim simulacijama pomoću kompjuterskih progama. 
Numeričke simulacije dvofaznih strujanja se koriste u cilju povećanja pouzdanosti i efikasnosti rada različitih generatora pare. U ovom radu je predstavljena uporedna analiza različitih načina modeliranja dvofaznog strujanja i razmene toplote u vertikalnom generatoru pare. Takođe, prikazani su različiti načini modeliranja međufazne sile trenja koji se koriste u komercijalnim softverima. Rezultati dobijeni numeričkom simulacijom su upoređeni sa izmerenim vrednostima dostupnim u literaturi.

\subsection{Ispitivani model}

Eksperimentalna instalacija koja je odabrana za simulaciju je skalirana verzija vertikalnog generatora pare tipa Westinghause Model F (Slika 1). Na ovoj instalaciji su zadržane geometrijske karakteristike, dok je produkcija pare skalirana na $1 \%$ produkcije originalnog modela. Detaljan prikaz instalacije je predstavljen u [1] i [2].

\section{Tabela 1. Termo-hidraulički parametri eksperimentalne instalacije}

\begin{tabular}{|l|r||}
\hline Snaga & $6,625 \mathrm{MW}$ \\
\hline Pritisak u parnom domu & $69,57 \mathrm{bar}$ \\
\hline Maseni protok sekundarnog fluida u jednoj grani & $5,64 \mathrm{~kg} / \mathrm{s}$ \\
\hline Ulazna temperatura sekundarnog fluida & $268,85{ }^{\circ} \mathrm{C}$ \\
\hline Pritisak u primarnom cirkulacionom kolu & $155,0 \mathrm{bar}$ \\
\hline Ulazna temperatura primarnog fluida & $325,1{ }^{\circ} \mathrm{C}$ \\
\hline Izlazna temperatura primarnog fluida & $293,3{ }^{\circ} \mathrm{C}$ \\
\hline Maseni protok primarnog fluida & $36,064 \mathrm{~kg} / \mathrm{s}$ \\
\hline
\end{tabular}

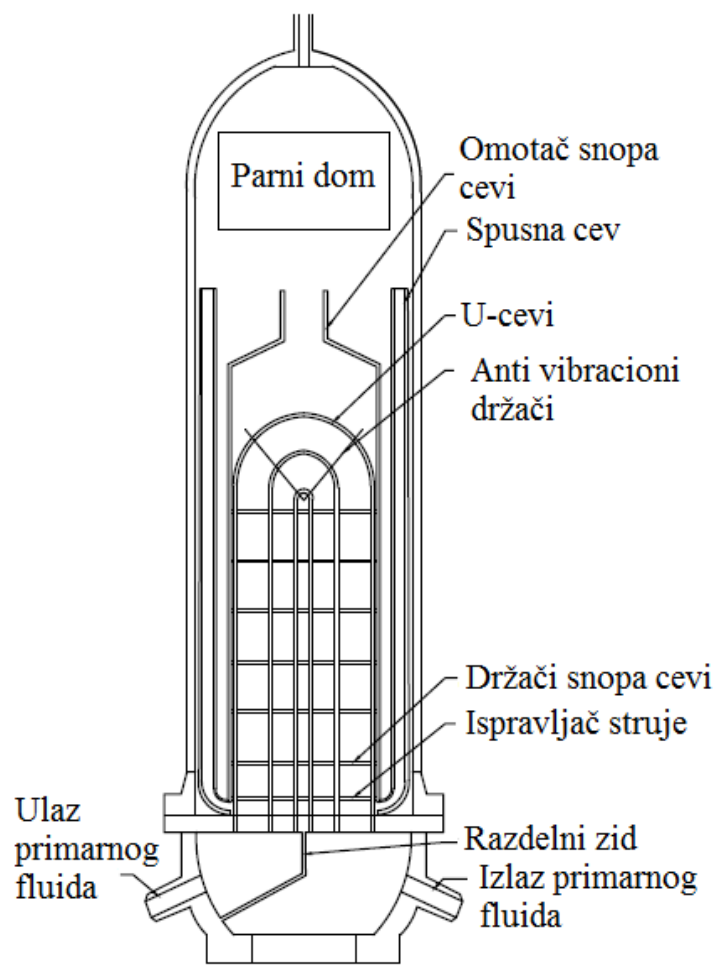

Slika 1. Šema eskperimentalne instalacije

\section{Matematički model}

Vertikalno strujanje dvofazne mešavine u generatoru pare se opisuje pomoću modela dva fluida koji se zasnovan na jednačinama bilansa mase, količine kretanja i energije, napisanim za svaku fazu pojedinačno. Indeks $\mathrm{k}=1 \mathrm{u}$ jednačinama označava tečnu fazu (vodu), dok indeks $\mathrm{k}=2$ označava gasnu fazu (vodenu paru). 
Koristi se koncept poroznih površina pri čemu se u kontolnoj zapremini mogu nalaziti tečna faza, parna faza i cevi.

Bilansne jednačine modela su:

- bilans mase

$$
\frac{\partial\left(\alpha_{k} \rho_{k}\right)}{\partial t}+\nabla \cdot\left(\alpha_{k} \rho_{k} \vec{u}_{k}\right)=(-1)^{k}\left(\Gamma_{i s p}-\Gamma_{k o n d}\right)
$$

-bilans količine kretanja

$$
\frac{\partial\left(\alpha_{k} \rho_{k} \vec{u}_{k} \vec{u}_{k}\right)}{\partial t}+\nabla \cdot\left(\alpha_{k} \rho_{k} \vec{u}_{k} \vec{u}_{k}\right)=-\alpha_{k} \nabla p+\alpha_{k} \rho_{k} \vec{g}+(-1)^{k+1} \vec{F}_{21}-\vec{F}_{3 k}+(-1)^{k}\left(\Gamma_{\text {isp }}-\Gamma_{k o n d}\right) \vec{u}_{1 i}
$$

$$
\frac{\partial\left(\alpha_{k} \rho_{k} h_{k}\right)}{\partial t}+\nabla \cdot\left(\alpha_{k} \rho_{k} h_{k} \vec{u}_{k}\right)=(-1)^{k}\left(\Gamma_{i s p}-\Gamma_{k o n d}\right) h^{\prime \prime}+\dot{q}_{3 k}
$$

Kao dodatna jednačina se uključuje i bilans zapreminskih udela

$$
\sum_{k=1}^{2} \alpha_{k}=1
$$

Bilansne jednačine (1)-(3) su date u neviskoznom obliku. Turbulentni viskozni efekti su obuhvaćeni indirektno preko keoficijenta trenja pri opstrujavanju snopa cevi i međufazne sile trenja između tečne i parne faze.

Usvojena je pretpostavka da se parna faza nalazi u stanju saturacije, pa se bilans energije rešava samo za tečnu fazu.

\subsection{Modeli razmene na međufaznim površinama}

Članovi sa desne strane bilansnih jednačina predstavljaju izvorne članove kojima se obuhvata međusobna interakcija faza, kao i interakcija faza sa zidovima generatora pare. Faze razmenjuju masu putem isparavanja, odnosno kondenzacije koji su posledica razmene toplote. Modeliranje ovih procesa se vrši uzimajući u obzir tzv. vreme relaksacije $\tau=0.05$ [2].

Isparavanje se odigrava kada specifična entalpije tečne faze postane veća od entalpije saturacije za dati radni pritisak $h_{1}>h^{\prime}, \alpha_{2}>0$ :

$$
\Gamma_{i s p}=\frac{\alpha_{1} \rho_{1}}{\tau} \frac{h_{1}-h^{\prime}}{h^{\prime \prime}-h^{\prime}}
$$

Kondenzacija je prisutna u slučaju kada se parna faza nađe u kontaktu sa pothlađenom tečnošću, tj. kada je specifična entalpija tečne faze manja od entalpije saturacije $h_{1}<h^{\prime}, \alpha_{2}>0$ :

$$
\Gamma_{\text {cond }}=\frac{\alpha_{2} \rho_{1}}{\tau} \frac{h^{\prime}-h_{1}}{h^{\prime \prime}-h^{\prime}}
$$

Strujno polje koje predstavlja rešenje jednačine količine kretanja zavisi kako od zapremisnke sile, tako i od interakcije među fazama i interakcije sa čvrstim zidovima generatora pare.

Razmena količne kretanja između faza prouzrokuje silu međufaznog trenja koja ima oblik:

$$
\vec{F}_{21}=\frac{3}{4} \alpha_{2} \rho_{1} \frac{C_{D}}{D_{p}}\left|\vec{u}_{2}-\vec{u}_{1}\right|\left(\vec{u}_{2}-\vec{u}_{1}\right)
$$

O modeliranju ove sile će više reči biti u poglavlju 4.

Interakcija pojedinačne faze sa črstim zidovima se modelira na osnovu pada pritiska koji je uzrokovan ovom preprekom:

$$
\vec{F}_{3 k}=\left(1-\alpha_{3}\right) \frac{\Delta p_{\mathrm{k}, e}}{\Delta e} \vec{e}, \vec{e} \in\{\vec{x}, \vec{y}\}
$$

Za strujanje paralelno U-cevima, ovaj pad pritiska iznosi: 


$$
\begin{gathered}
\Delta p_{1, e}=\zeta_{1, e} \frac{\rho_{1} \hat{u}_{1, e}^{2}}{2}(1-\varphi) \\
\Delta p_{2, e}=\zeta_{2, e} \frac{\rho_{2} \hat{u}_{2, e}^{2}}{2} \varphi \\
\hat{u}_{k, e}=\frac{u_{k, e}}{1-\frac{d_{c s}}{P_{e}}} \\
\zeta=\left\{\begin{array}{l}
\frac{64}{\operatorname{Re}} \frac{\Delta e}{d_{c s}}, \operatorname{Re}=\frac{\hat{u}_{k, e} d_{c s}}{v_{k}}<4 \cdot 10^{3} \\
\frac{0.316}{\operatorname{Re}} \frac{\Delta e}{d_{c s}}, \operatorname{Re}=\frac{\hat{u}_{k, e} d_{c s}}{v_{k}} \geq 4 \cdot 10^{3}
\end{array}\right.
\end{gathered}
$$

Pad pritiska za poprečno nastrujavanje iznosi:

$$
\Delta p_{k}=\rho u_{k}^{2} \cdot E u, \quad E u=1.4(1+z)\left(\frac{\left|u_{k}\right| d_{c s}}{v_{k}}\right)^{-0.25}
$$

Razmena energije između faza je obuhvaćena putem transfera mase, koju odlikuje specifična entalpija. Na osnovu razmatranja sistema jednačina (1)-(4), kao i izvornih članova, moguće je uvideti da dominantan uticaj imaju toplotni fluks na tečnu fazu $q_{3 l}$, koji dovodi do stvaranja parne faze, kao i sila međufaznog trenja $F_{2 l}$ koja oblikuje strujno polje.

\section{Jednodimenzijski model razmene toplote}

Razmena toplote sa primarnog na sekundarni fluid je određena razlikom temperatura primarnog i sekundarnog fluida, strujno-geometrijskim parametrima i fizičkim osobinama fluida. Imajući u vidu da je osnovna funkcija generatora pare razmena toplote, pravilno predviđanje toplotnog fluksa je od velikog značaja za simulaciju radnih uslova u generatoru pare.

Jednačine koje opisuju ovu razmenu toplote se pišu u jednodimenzijskom obliku i diskretizuju numeričkom metodom konačnih zapremina, koja je napisana za jednu U-cev (smatra se da sve U-cevi predaju istu količinu toplote). Novodobijeni sistem algebarskih jednačina se rešava za stacionarne uslove. Dobijeni rezultati su ulazni podaci za numerički model generatora pare kako bi bila izvršena simulacija.

\subsection{Predvidanje toplotnog fluksa}

Rešavaju se energetske jednačine napisane u jednodimenzijskom obliku:

- Za primarni fluid:

$$
\frac{\partial h_{1}}{\partial x}=-\frac{Q_{l}}{\dot{m}_{1}}
$$

- Za sekundarni fluid:

$$
\frac{\partial h_{2}}{\partial x}=\frac{Q_{l}}{\dot{m}_{2}}
$$

Pri čemu je x-podužna koordinata, merena paraleleno osi U-cevi.

Primarni fluid je izložen neprekidnom hlađenju, pa jedini mehanizam razmene toplote sa primarne strane jeste prinudna konvekcija:

$$
Q_{1 w}=h_{1} \cdot\left(\mathrm{T}_{1}-\mathrm{T}_{w 1}\right) \cdot d_{c u} \cdot \pi \cdot d x
$$


$\mathrm{Na}$ ulazu u podizni kanal temperatura sekudnarnog fluida je niža od temperature saturacije, pa se razmena toplote odvija pod uticajem mehanizma prinudne konvekcije:

$$
Q_{w 2}=h_{2} \cdot\left(\mathrm{T}_{w 2}-\mathrm{T}_{2}\right) \cdot d_{c s} \cdot \pi \cdot d x
$$

Jednačina (17) ima identičan oblik i u slučaju zasićenog mehurastog ključanja, uz razliku pri modeliranju koeficijenta $h_{2}$.

Usled razmene toplote dolazi do porasta temperature zida na sekundarnoj strani $T_{w 2}$. Kada temperatura zida poraste dovoljno iznad temperature saturacije sekundarnog fluida, dolazi do pothlađenog ključanja, pri čemu se proces razmene toplote intenzivira, obuhvatajući kako uticaj prinudne konvekcije, tako i uticaj razmene toplote usled mehurastog ključanja:

$$
Q_{w 2}=d_{c s} \cdot \pi \cdot d x \cdot\left[h_{2} \cdot\left(\mathrm{T}_{w 2}-\mathrm{T}_{2}\right)+h_{s n b} \cdot\left(\mathrm{T}_{w 2}-\mathrm{T}_{s a t}\right)\right]
$$

Kada se srednja temperatura sekundarnog fluida izjednači sa temperaturom saturacije, dolazi do zasićenog mehurastog ključanja, pri čemu je prenos toplote dat relacijom:

$$
Q_{w 2}=d_{c s} \cdot \pi \cdot d x \cdot h_{n b} \cdot\left(\mathrm{T}_{w 2}-\mathrm{T}_{s a t}\right)
$$

Objedinjavanjem jednačina (16)-(19), uz uvrštavanje modela kondukcije kroz cilindričan zid, dobija se opšta jednačina za proračun toplotnog fluksa:

$$
Q=k \cdot\left[\left(\mathrm{T}_{1}-\mathrm{T}_{2}\right)+\frac{h_{s n b}}{h_{2}} \cdot\left(\mathrm{T}_{w}-\mathrm{T}_{s a t}\right)\right]
$$

gde je $k$, ukupni koeficijent prolaza toplote :

$$
k=\frac{1}{\frac{1}{h_{1}}\left(\frac{d_{c s}}{d_{c u}}\right)+\frac{d_{c s}}{2 \lambda} \ln \left(\frac{d_{c s}}{d_{c u}}\right)+\frac{1}{h_{2}}}
$$

Koeficijent prelaza toplote pri pothlađenom ključanju $h_{s n b}$ ima vrednost različitu od nule samo u slučaju pothlađenog ključanja, dok se za zasićeno mehurasto ključanje primenjuje relacija: $h_{2}=h_{n b}$

\subsection{Modeliranje koeficijenata prelaza toplote}

Za predaju toplote sa primarnog fluida na unutrašnji zid cevi, koristi se Dittus-Boelter (1930) korelacija, izvorno napisana za turbulentno strujanje u cevima kružnog poprečnog preseka:

$$
h_{1}=0.023 \cdot \frac{\lambda}{D_{h}} \cdot \operatorname{Re}^{0.8} \cdot \operatorname{Pr}^{0.4}
$$

Konvektivni koeficijent za sekudarni fluid se računa modifikovanom Dittus-Boelter korelacijom za strujanje u cevnom snopu prema preporuci iz [6] :

$$
h_{2}=0.023 \cdot \frac{P_{c}}{d_{c s}} \cdot \frac{\lambda}{D_{h}} \cdot \operatorname{Re}^{0.8} \cdot \operatorname{Pr}^{0.3}
$$

gde su $P_{c}$-korak a $d_{c s}$ spoljašnji prečnik cevi.

Koeficijent prelaza toplote pri pothlađenom ključanju se računa prema Chen-ovoj korelaciji:

$$
h_{s n b}=S_{s u b} \cdot S_{f z} \cdot h_{f z}
$$

Prema ovom modelu, smatra se da je pothlađeno ključanje analogno zasićenom mehurastom, pri čemu se ono mora ponderisati težinskim faktorima $S_{s u b}$ i $S_{f z}$.

Ovi faktori uzimaju u obzir makro karakteristike strujanja sekundarnog fluida, s obzirom da je razmena toplote pri pothlađenom ključanju i dalje zavisna od strujnih faktora [4]:

$$
S_{s u b} \cdot S_{f z}=\frac{1}{1+2.53 \cdot 10^{-6} \cdot \operatorname{Re}_{l}^{1.17}} \cdot \frac{T_{w}-T_{s a t}}{T_{w}-T_{2}}
$$

Koeficijent prelaza toplote pri zasićenom mehurastom ključanju se računa prema korelaciji Foster-Zuber: 


$$
h_{f z}=\Delta T_{\text {sat }}^{i}{ }^{0.25} \cdot \Delta p_{\text {sat }}^{i} 0.75 \cdot \frac{c p_{l}^{0.45} \cdot \rho_{l}^{0.49} \cdot \lambda_{l}^{0.79}}{\sigma^{0.5} \cdot h_{\mathrm{lg}}^{0.24} \cdot \mu_{l}^{0.29} \cdot \rho_{\mathrm{g}}^{0.24}}
$$

Pothlađeno ključanje se odvija ukoliko je srednja temperatura fluida niža, a temperatura spoljašnjeg zida U-cevi viša u odnosu na temperaturu saturacije. Potrebna temperaturska razlika zida cevi se određuje poznavajući toplotni fluks sa zida na pothlađenu tečnost, kao i temperaturu zida:

$$
\Delta T=\sqrt{\frac{8 \cdot \sigma \cdot T_{s a t} \cdot q_{a}}{h_{\mathrm{lg}} \cdot \rho_{\mathrm{g}} \cdot \lambda_{l}}}
$$

Kada flud dostigne stanje saturacije, smatra se da počinje zasićeno mehurasto ključanje, koje se modelira prema korelaciji Rassohin (1987), koja je preporučena prema [3] :

$$
\begin{gathered}
h_{2}=f(p) \cdot q_{A}^{0.7} \\
f(p)=4.32 \cdot\left(p^{0.14}+1.28 \cdot 10^{-2} \cdot p^{2}\right)
\end{gathered}
$$

Sistem jednačina uz korelacije se rešava numeričkom metodom konačnih zapremina, napisanim u jednodimenzijskom obliku.

\section{Modeliranje sile međufaznog trenja}

Međufazno trenje je izraženo kada postoji razlika brzina između faza, pri čemu dolazi do razmene količine kretanja na kontaktnim površinama. Sila međufaznog trenja u slučaju vertikalnog strujanja naviše deluje suprotnosmerno od smera kretanja parne faze, usporavajući je, na račun povećanja brzine tečne faze. Međufazno trenje ima veliki uticaj na krajnji izgled brzinskog i polja pritiska, a posredno ima uticaj i na distribuciju drugih termohidrauličkih parmetara.

Modeliranje ove sile nije do kraja zaokružen problem, pa u literaturi različiti autori predlažu uglavnom poluempirijske korelacije i modele. Većina ovih modela na različite načine obuhvata uticaje kocijenta otpora $C_{D}$ i prečnika dispregovanih čestica $D_{p}$

\subsection{Modeli iz komericijalnih paketa za CFD simulacijet}

Programski paket ANSYS Fluent predstavlja inženjerski alat koji se koristi za proračun i dizajn termohidrauličkih uređaja, baziran na primeni CFD simulacija. Ukoliko se želi izbeći korišćenje korisničkih funkcija (UDF), podrška pri modeliranju dvofaznih strujanja sadrži mnogobrojna uprošćenja. Prema [5] smatra se da se sekundarna faza može nalaziti jedino u obliku dispergovanih čestica uniformnog prečnika (mehurasti tok neprekidno preovladava) koji može biti iskustveno zadat od strane korisnika, ili se pak može koristiti Unal korelacija prema kojoj prečnik dispergovane čestice zavisi od temperature pothlađenja fluida, i za stanje saturacije iznosi $D_{p}=1,5 \mathrm{~mm}$.

\subsubsection{Model Shiller-Naumann}

Ovaj model prema [5] je standardni model za proračun dvofaznih sistema fluid-dispergovana čestica, pri čemu se koeficijent trenja računa kao:

$$
C_{D}=\left\{\begin{array}{cc}
24 \cdot\left(1+0.15 \cdot \mathrm{Re}^{0.687}\right) / \mathrm{Re} & \mathrm{Re} \leq 1000 \\
0.44 & \mathrm{Re}>1000
\end{array}\right.
$$

gde je Re- Rejnoldsov broj koji se modelira kao:

$$
\operatorname{Re}=\frac{\rho_{2}\left|\vec{u}_{2}-\vec{u}_{1}\right| D_{p}}{\mu_{1}}
$$

\subsubsection{Model Ishii}

Ovaj model za vrednost koeficijenta trenja uzima minimum za tzv. viskozni i distorzni režim: 


$$
\begin{gathered}
C_{D}=\min \left(C_{D}^{v i s}, C_{D}^{d i s}\right) \\
C_{D}^{v i s}=\frac{24}{\operatorname{Re}}\left(1+0.15 \operatorname{Re}^{0.75}\right) C_{D}^{d i s}=\frac{2}{3} \cdot \frac{D_{p}}{\sqrt{\frac{\sigma}{g \cdot\left|\rho_{1}-\rho_{2}\right|}}}
\end{gathered}
$$

\subsubsection{Model Tomiyama}

Ovaj model uzima u obzir i mogući nesferičan oblik dispergovanih čestica, odnosno mehurova, što je obuhvaćeno Eotsovim brojem:

$$
C_{D}=\max \left(\min \left(\frac{24}{\operatorname{Re}}\left(1+0.15 \mathrm{Re}^{0.687}\right), \frac{72}{\operatorname{Re}}\right), \frac{8}{3} \cdot \frac{E o}{E o+4}\right), \quad E o=\frac{g \cdot\left(\rho_{1}-\rho_{2}\right) D_{p}^{2}}{\sigma}
$$

\subsection{Model iz sopstvenog programskog paketa}

Korelacija Ishii-Zuber predstavlja često korišćen model pri poračunu sile međufaznog trenja.

Određivanje režima strujanja se obavlja putem parametra $\varphi$ :

$$
\varphi=\frac{\alpha_{2}}{\alpha_{1}+\alpha_{2}}
$$

Ako je $\varphi \leq 0,3$, smatra se da je nastupio mehurasti tok, a ukoliko je $0,3<\varphi \leq 1,0$, smatra se da tok ima penasto-turbulentni oblik.

Koeficijent trenja se za mehurasti tok računa kao:

$$
C_{D}=0.267 \cdot D_{p} \cdot\left(\frac{g \Delta \rho}{\sigma}\right)^{\frac{1}{2}}\left(\frac{1+17.67 f(\varphi)^{\frac{6}{7}}}{18.67 f(\varphi)}\right)^{2}
$$

Za penasto-turbulentni se računa kao:

$$
C_{D}=1.487 \cdot D_{p} \cdot\left(\frac{g \Delta \rho}{\sigma}\right)^{\frac{1}{2}}(1-\varphi)^{3}(1-0.75 \varphi)^{2}
$$

\section{Primena numeričkog postupka}

Opisane bilansne jednačine (1)-(3) čine sistem parcijalnih diferencijalnih jednačina čije rešenje nije moguće analitičkim putem, pa se za njihovo rešavanje koriste numeričke metode konačnih zapremina. Skalarne veličine (temperatura, pritisak, zapreminski udeo, entalpija) se rešavaju u centirma kontrolnih zapremina, dok se brzine računaju na njihovim površima primenom pomerenih kontrolnih zapremina.

Za rešavanje sistema algebarskih jednačina se koristi numerički algoritam SIMPLE (Semi Implicit Algorithm for Pressure Linqed Equations), sa sledećim koracima :

1. Pretpostaviti početno polje svih veličina,

2. Izračunati polja skalarnih veličina (zapreminski udeo faza, entalpija),

3. Izračunati polja brzina za svaku fazu,

4. Korigovati polje pritiska rešavanjem jednačine kontinuiteta sa izračunatim brzinama,

5. Korigovati polja brzina sa novoizračunatim pritiskom,

6. Ponavljati korake 2. do 5. sve do zadovoljenja jednačine kontinuiteta,

7. Po zadovoljenju jednačine kontinuiteta, povećati vreme i promeniti početne parametre,

8. Ponavljati opisani postupak sve do kraja predviđenog vremenskog procesa. 


\section{$6 \quad$ Prikaz i diskusija rezultata}

\subsection{Predikcija fluksa i temperatura}

Dati su rezultati proračuna po numeričkom algoritmu koji je izložen u poglavlju 3.

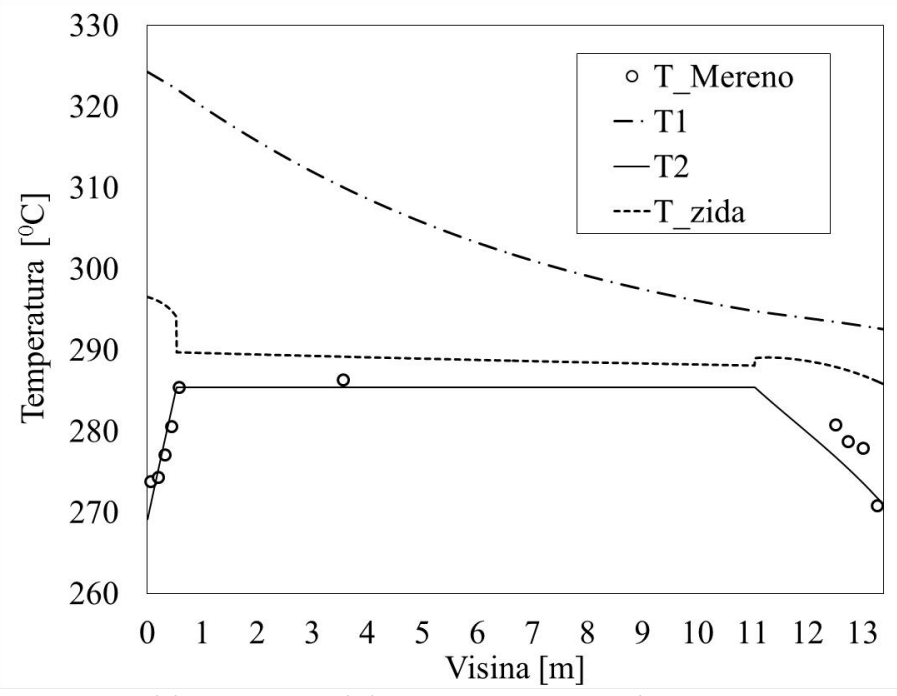

Slika 2. Raspodela temperatura po dužini U-cevi

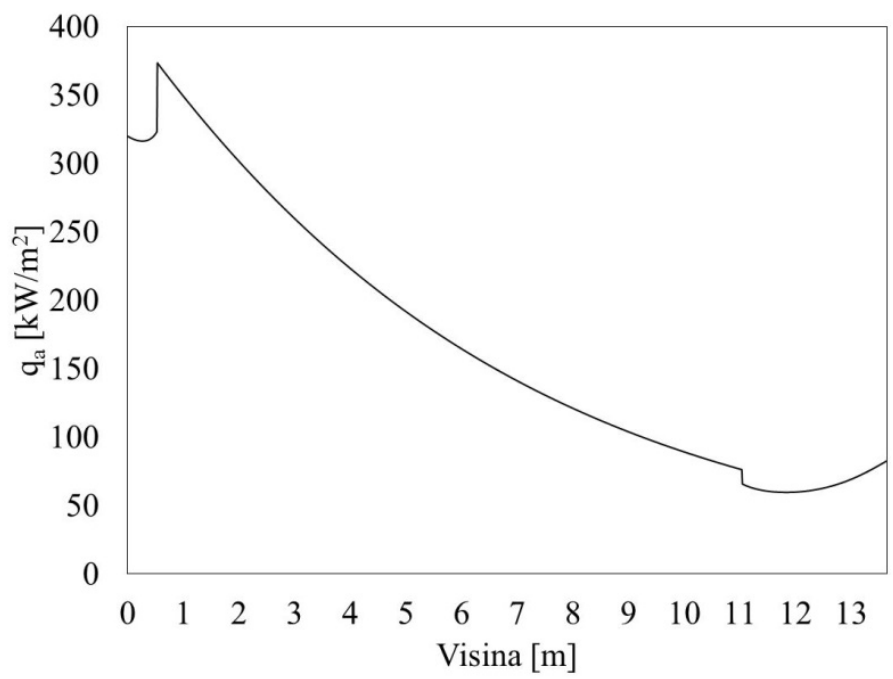

Slika 3. Raspodela površinskog toplotnog fluksa po dužini U-cevi

Korišćeni model pokazuje dobru predikciju razmene toplote na liniji zagrevanja na toploj grani dok do određenog odstupanja dolazi na hladnoj grani.

\subsection{Predikcija zapreminskog udela pare $\mathrm{i}$ brzinskog polja parne faze}

Nezavisno od korišćenog modela sile međufaznog trenja, dolazi do rasta zapreminskog udela parne faze usled predaje toplote $\mathrm{i}$ isparavanja. Duž visine U-cevi, polje zapreminskog udela pare zavisi kako od procesa predaje toplote, tako i od korišćenog modela sile međufaznog trenja, dok u prostoru iznad U-cevi ono zavisi samo od sile međufaznog trenja. Parna faza se odlikuje znatno manjom gustinom u odnosu na tečnu, pa sa porastom zapreminskog udela raste i njena brzina. Brzinsko polje parne faze je zanemarivog intenziteta na liniji zagrevanja, da bi se postepeno intenziviralo do vrha generatora pare. 
6.2.1 Modeli iz programskog paketa ANSYS Fluent
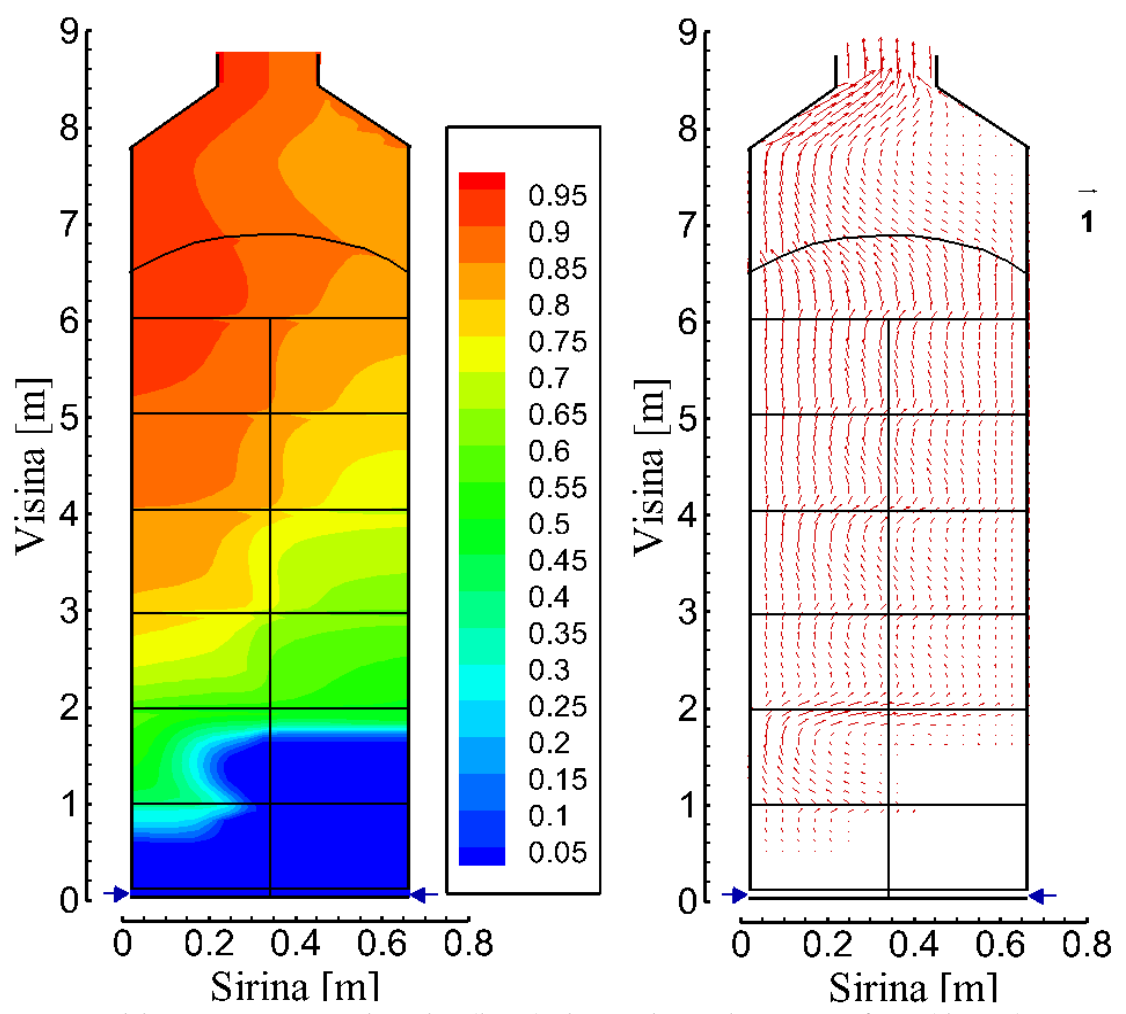

Slika 4. Zapremisnki udeo(levo)i brzinsko polje parne faze (desno)

\subsubsection{Model iz sopstvenog programskog paketa}
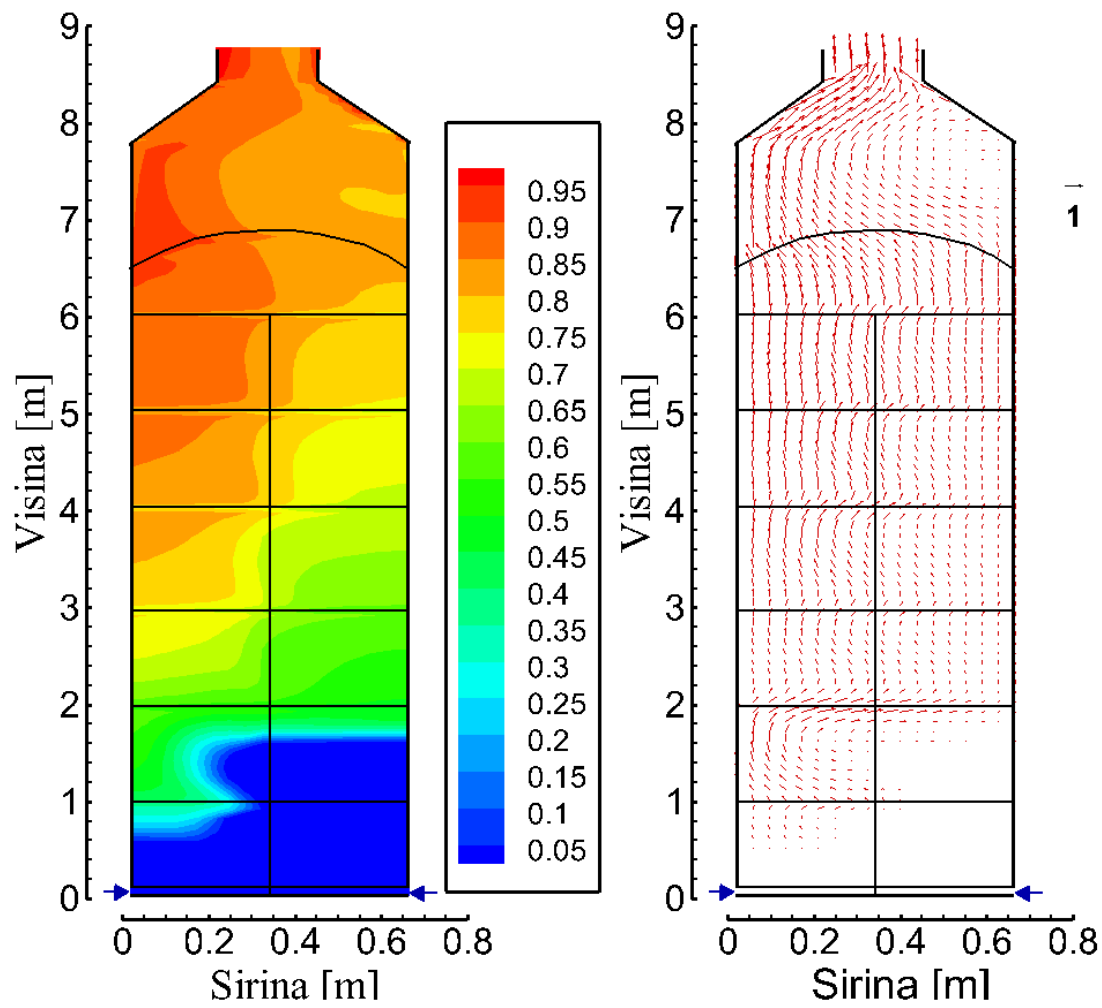

Slika 5. Zapremisnki udeo(levo)i brzinsko polje parne faze (desno)

Korelacije za međufaznu silu trenja koje se koriste u programskom paketu ANSYS Fluent predviđaju veće vrednosti zapreminskog udela parne faze u gornjim delovima generatora pare. Razlika u 
prenesenoj količini toplote između tople i hladne grane utiče na intenzivnije generisanje parne faze $u$ toploj grani nego na hladnoj. Takođe, kao posledica se javlja i razlika u brzinskom polju između tople i hladne grane, što dovodi do vrtložnog kretanja u gornjoj zoni hladne grane. Sa druge strane korelacija Ishii-Zuber daje nešto niže vrednosti zapreminskog udela pare na izlazu iz generatora pare i pogodnija je za numeričku simulaciju u dvodimenzionalnom prostoru.

\section{$7 \quad$ Zaključak}

Razvijen je model razmene toplote pri strujanju dvofazne mešavine vode i pare oko snopa cevi $\mathrm{u}$ vertikalnom generatoru pare, pri čemu su razmatrane oblasti prinudne konvekcije, pothlađenog ključanja, kao i zasićenog mehurastog ključanja. Rezultati predviđanja toplotnog fluksa pokazuju dobro slaganje sa izmerenim rezultatima na toploj grani. Predikcija toplotnog fluksa je naknadno implementirana u numerički model za simulaciju strujanja u vertikalnom generatoru pare. Ovaj model je zanosvan na jednačinama bilansa mase, količine kretanja i energije, uz korišćenje konstitutivnih korelacija. Rešavanje pomenutog sistema jednačina je izvršeno primenom numeričkog algoritma SIMPLE. Izvršeno je poređenje različitih korelacija za silu međufaznog trenja, koje su prisutne u komercijalnim programskim paketima za simulacije dvofaznog strujanja. Dobijeni rezultati su upoređeni sa podacima dostupnim u literaturi i pokazano je zadovoljavajuće slaganje. Razvijeni model služi kao podrška projektovanju vertikalnih generatora pare.

\section{$8 \quad$ Literatura}

[1] Hilberg S., An Assessment of TRACE V5 RC1 Code Separator Model with the Westinghouse Model Boiler 2 Experiments, U.S. Nuclear Regulatory Commission, Washington DC, USA, 2010

[2] Green S.J., Hetsroni G., PWR STEAM GENERATORS, Int. J. Multiphase Flow, 1995, 21, str. 1-97, 1995

[3] Maslarović B., Numerička Simulacija Dvodimenzijskog Dvofaznog Strujanja u Vertikalnom Generatoru, Diplomski rad, Mašinski Fakultet,Beograd, Republika Srbija, 2002

[4] Steiner H., Kobor A., Gebhard L., A wall heat transfer model for subcooled boiling flow, International Journal of Heat and Mass Transfer, 2005, 48, str. 4161-4173, 2005

[5] ***, ANSYS Fluent Theory Guide, ANSYS, Inc., 2013

[6] ***, RELAP5/MOD3.3 CODE MANUAL, Information Systems Laboratories Inc., 2001 